NBER WORKING PAPER SERIES

\title{
UNCERTAIN PARAMETER VALUES AND THE CHOICE AMONG POLICY OPTIONS
}

Don Fullerton

Andrew B. Lyon

Working Paper No. 1111

NATIONAL BUREAU OF ECONOMIC RESEARCH

1050 Massachusetts Avenue

Cambridge MA 02138

April 1983

We wish to thank Charles L. Ballard, Yolanda K. Henderson, John B. Shoven, and John Whalley for help with this research and for useful suggestions. Financial assistance was provided by the Treasury Department's Office of Tax Analysis, Princeton University, and the National Science Foundation under grant SES 8025404. The research reported here is part of the NBER's research program in Taxation and project in Government Budget. Any opinions expressed are those of the authors and not those of the National Bureau of Economic Research. 
Uncertain Parameter Values and the

Choice Among Policy Options

\section{ABSTRACI}

In this paper, we use tax policy choices to illustrate and investigate the more general problem of using uncertain parameter values in models to evaluate policy choices. We show, for this tax example, how debate on an elasticity parameter translates into a debate about policy choices, and vice versa. To construct this example, we suppose that the choice among four particular tax reform options is based on a single measure of efficiency gain. We show how this gain from each reform depends upon the elasticity of saving with respect to the net rate of return. Within quite narrow and reasonable bounds for the elasticity parameter, we find regions in which each of three different tax reforms turns out to dominate the others.

Don Fullerton Andrew B. Lyon Woodrow Wilson School Princeton University Princeton, NJ 08544 (609) 452-4811 


\section{Introduction}

The optimal tax literature provides valuable rules for designing tax reform to minimize the cost of distortions in economic choices. Yet the theory alone does not provide guidance on whether, for example, current tax rates on capital or labor are too high or too low relative to the optimum rates. Without appropriate estimates of the underlying economic parameters, the best direction for tax reform is ambiguous.

In this paper, we use tax policy choices to illustrate and investigate the more general problem of using uncertain parameter values in models to evaluate policy choices. We show, for this tax example, how debate on an elasticity parameter translates into a debate about policy choices, and vice versa. To construct this example, we suppose that the choice among four particular tax reform options is based on a single measure of efficiency gain. We show how this gain from each reform depends upon the elasticity of saving with respect to the net rate of return. Within quite narrow and reasonable bounds for the elasticity parameter, we find regions in which each of three different tax reforms turns out to dominate the others.

In the sections that follow, we briefly discuss the theoretical importance of the saving elasticity in determining intertemporal welfare effects of taxes on income from capital; empirical estimates of this elasticity; the interaction of intertemporal distortions with intersectoral and labor/leisure distortions; and the results of simulating four potential tax reforms in a general equilibrium model that accounts for these considerations. 


\section{Efficiency and Elasticity Parameters}

Consider a single commodity $x$, produced at constant cost $P$, and taxed at the ad valorem tax rate $t$. If $\varepsilon$ is the compensated demand elasticity, then the welfare gain or loss from the tax may be written as $W(\varepsilon, t)$. In a partial equilibrium model where $t$ is very small,

$$
W=\frac{1}{2} \varepsilon t^{2} X P
$$

This equation can be used to measure the intertemporal distortions resulting from the taxation of income from capital. When an after-tax dollar of earnings is saved, it earns a return that is taxed again by the personal income tax system. Additionally, if this dollar is invested in the corporate sector, a separate corporate tax is imposed before the return is paid out. These taxes raise the price of future consumption relative to the price of present consumption. The welfare cost of this distortion may be measured using equation (1), where $X$ and $P$ are the quantity and price of future consumption, $t$ is the additional tax on future consumption, and $\varepsilon$ is the price elasticity of demand for future consumption. Discussion of taxation and saving has often centered around a different parameter, $n$, the elasticity of saving with respect to the net rate of return. Martin Feldstein (1978) has clarified two distinctions between $\eta$ and $\varepsilon$. First, $\varepsilon$ reflects a change in $\mathrm{X}$, the quantity of future consumption, while $\eta$ reflects a change in saving, the expenditure on future consumption. If this expenditure is to remain constant (the case where $\eta=0$ ), then quantity must adjust to offset any change in price. A zero saving elasticity therefore implies a nonzero quantity elasticity. Second, $\eta$ is usually measured as an uncompensated elasticity, while $\varepsilon$ in equation (1) should 
reflect a compensated elasticity. Nonzero income effects imply further differences.

These considerations can be used to derive a linear relationship between $\varepsilon$ and $\eta$. This relationship points to a substantial error that can occur from using $n$ directly in (1). In particular, a zero saving elasticity may be associated with substantially nonzero welfare costs from taxes on income from capital. Estimates of the saving elasticity are discussed and employed below, but our model always converts each value of $\eta$ into a corresponding value for $\varepsilon$ before it calculates $W$.

We calculate the welfare gains from each of four tax reforms below, and we show how these gains depend on the assumed value of $n$. If the reforms are compared on the basis of welfare gains, their relative positions also depend on $n$. As a secondary objective, we also discuss how uncertainty in the elasticity estimate affects the expected value of the welfare gain. In any application of equation (1), $\varepsilon$ may be measured with error. Policy recommendations should then be based on $E[W(\varepsilon, t)]$, where $E$ is the expectations operator. Instead, analysts typically estimate $W[E(\varepsilon), t]$ in order to employ a single estimated value for the elasticity parameter. This shortcut is perfectly valid in the partial equilibrium model represented by equation (1): $W$ is a linear function of $\varepsilon$, so $E[W(\varepsilon, t)]=W[E(\varepsilon), t]$. Many general equilibrium studies continue to use $E(\varepsilon)$ to evaluate large tax changes, however, including the study by Fullerton, King, Shoven, and Whalley (1981). We investigate the size of this error by using the same model to $\mathrm{plot} W$ as a function of the saving elasticity. If this relationship is nearly linear, then the effect of the error is small. 


\section{Empirical Estimates of the Saving Elasticity}

An increase in the net rate of return lowers the price of future consumption. The compensated quantity demanded must rise, but the percentage increase may exceed or fall short of the percentage decrease in price. Expenditure on future consumption (saving) may rise or fall, so the sign of $n$ is ambiguous.

Empirical estimates of $n$ have hardly narrowed the range of plausible values. "Denison's Law" states that $n$ is zero, following Edward Denison's (1958) observation that saving as a fraction of income in the U.S. has been a historical constant. Econometric estimates by Michael Boskin (1978) suggest that $n$ is significantly positive. Using eight different regressions, Boskin finds values for $n$ that range from 0.2 to 0.6 , but that cluster between 0.3 and 0.4. Howrey and Hymans (1978) use Boskin's data but find that estimates of $n$ are sensitive to (1) the measure of expected inflation, (2) the sample period, (3) the definition of saving, and (4) the interest rate variable chosen for the regression. They cannot reject the hypothesis that $n$ is zero.

More recently, Lawrence Summers (1981) builds a model in which lifetime consumption plans depend upon intertemporal substitution in utility, time until retirement and death, the rate of time preference, rates of growth, and the rate of return to saving. The model is then solved for the saving elasticity. Plausible values for these other parameters imply values for $n$ from 1.5 to 3.0 , a range much higher than those of the econometric estimates described above. Finally, David Starrett (1982) shows how amendments to Summers' model could widen these bounds still further, but he argues for values of $n$ that are lower than those found by Summers. 1 ' 


\section{Efficiency Analysis with Several Distortions}

For each different value of $n$, we use a computational model of the U.S. economy and tax system to measure the welfare gains from four separate tax reform proposals. $2 /$ In the tradition of Harberger (1962, 1966), this model abstracts entirely from the costs of implementing or administering alternative tax proposals. It includes 19 different industries, each with a Constant Elasticity of Substitution (CES) production function defined over capital, labor, and the outputs of other industries. Capital is homogeneous and mobile, and it faces an ad valorem rate of tax in each industry that reflects corporate taxes, property taxes, and personal taxes. Differing rates of tax create distortions in the allocation of capital among industries, so efficiency can be enhanced by any reform that tends to remove tax rate disparities. In fact, for a fixed stock of capital in any one period, any common rate of tax on all uses of capital is nondistorting. Each of 12 different income classes has an endowment of labor and capital, and is assigned a nested CES utility function defined over future consumption, present consumption, and leisure. The model allows the user to specify any value for the wage elasticity of labor supply and any value for the interest elasticity of saving. It then calculates parameters for the twelve utility functions such that utility maximization behavior is consistent with those elasticities. Government uses revenues in a balanced budget to purchase industry outputs, to make transfer payments, and to subsidize government enterprises. A trade sector closes the model.

Total saving in each equilibrium is used to augment the capital stock in successive equilibria. We choose an exogenous rate of growth for effective labor units, such that a simulation with unchanged tax rules provides a sequence of equilibria that lies on a steady state growth path. A simulation with an alternative tax rule provides a sequence of equilibria that 
approaches a different steady state growth path, with a different capital/ labor ratio for the economy. Intertemporal and other distortions are then measured by comparing the discounted stream of consumption from each sequence. Aggregate welfare differences are defined by the present value of compensating variations, in 1973 dollars. $\underline{3}$ /

When tax rules are altered for a simulation, we scale all personal income tax rates up or down in order to keep the government's budget balanced at the same level of real expenditures and transfer payments. Any change in an industry's tax on capital thus affects intersectoral distortions through the dispersion of tax rates by industry, intertemporal distortions through the overall average rate of tax on capital, and labor/ leisure distortions through the personal taxes required to maintain real revenue yields. As a consequence, the model is fully capable of secondbest efficiency analysis in a world where nondistorting taxes are generally unavailable. In such a world, the comparative advantages of alternative tax reforms depend on a large set of behavioral parameters. In this paper, of course, we provide total welfare gains as a function of the saving elasticity. 4 /

\section{Tax Reform Simulations}

To demonstrate the relationships discussed above, we select four particular tax reforms to evaluate. Our selection is essentially arbitrary, but we wish to look at feasible reforms that are currently under consideration by at least some economists and policymakers.

1. Tax Imputed Rents. Homeowners earn a return to their investment that currently escapes both corporate and personal taxation. This reform raises the low rate of tax on capital in the housing industry, reduces 
the dispersion of rates, and provides an intersectoral efficiency gain. By raising more revenue, the government can also reduce the personal income tax distortions in labor/leisure choices. By raising the overall rate of tax on capital, however, this reform implies intertemporal losses that increase in importance with the saving elasticity. Figure 1 shows that gains outweigh losses for all values of $n$ between zero and 0.6 , but that the net gain falls from $\$ 256$ billion to $\$ 126$ billion across this range of elasticity values. Because intertemporal losses are small for low $n$, this reform dominates the others for $\eta<0.18$.

2. Index Capital Gains. In the current system, taxes are paid on 40 percent of real capital gains as well as on inflationary increases in share prices and other asset values. This reform removes inflationary gains from the tax base and reduces the overall taxation of income from capital. It thus provides intertemporal gains that increase with $n$. It changes industry tax rates differentially and has an ambiguous impact on intersectoral distortions, but the revenue loss requires additional distorting personal taxes on labor. Figure 1 shows how the net gain increases from $\$ 18$ billion to $\$ 185$ billion, but this reform by itself never dominates all the others.

3. Integrate Income Taxes. Since industries differ in the degree to which firms are incorporated, separate corporate taxes raise effective rates in some industries more than others. This reform eliminates the separate corporate tax system, but collects personal tax on retained as well as distributed profits of corporations. It lowers the highest rates of tax on capital and thus provides both intersectoral and intertemporal gains. Figure 1 shows how these gains outweigh additional distortions in the labor/leisure choice, with net gains rising from $\$ 122$ to $\$ 393$ billion 
as $\eta$ is increased from zero to 0.6. Efficiency gains are larger than those of any other reform when $n$ is between 0.18 and 0.29 .

4. Integrate and Index. This reform combines those of 2 and 3 above, and it provides the greatest reduction of taxes on income from capital. With a zero saving elasticity, these intertemporal gains are relatively unimportant. The large shortfall in revenue, however, requires major increases in personal taxes that add to important labor/leisure distortions. Net gains are on $1 y$ \$ $\$ 3$ billion, but these increase dramatically to $\$ 481$ billion as $n$ increase to 0.6 . For values of $n>0.29$, intertemporal gains outweigh other losses by enough that this reform dominates all others. This curve in Figure 1 is not the vertical sum of the curves from reforms 2 and 3 , because the combined revenue shortfall requires an increase in the personal tax rate that enters quadratically in the cost of labor/leisure distortions.

Figure 1 further indicates that the first curve is practically linear, though slightly convex. The other three are practically linear, though slightly concave. If the distribution of possible values for $n$ is symmetric around 0.4 , for example, these results indicate that the correct expected welfare gain from reducing taxes on capital is slightly less than the welfare gain obtained with the use of $n=0.4$ alone. Thus, when Fullerton, King, Shoven, and Whalley (1981) report results for reforms 3 and 4, the effect of this error is very small. By using only 0.4 , however, they may leave the misimpression that integration with indexing always dominates integration alone in this model. 


\section{Conclusion}

In this paper, we use a general equilibrium simulation model to rank four possible tax reforms on the basis of a measure of economic efficiency that includes the intersectoral allocation of capital, the intertemporal allocation of consumption, and the labor/leisure allocations of individuals. The welfare gain from each tax reform is an almost linear function of the saving elasticity assumed in the model, and we show the sensitivity. Moreover, even within the relatively narrow region between zero and 0.6 , we find values of the saving elasticity for which each of three different tax reforms is ranked highest.

One interpretation of this result is that until theorists such as . Summers (1981) and Starrett (1982) agree on a concept for the saving elasticity, and until econometricians such as Boskin (1978) and Howrey and Hymans (1978) agree on an estimate for the saving elasticity, those of us who use this parameter to simulate tax reforms cannot hope to provide unambiguous recommendations to policymakers. Furthermore, because the saving elasticity is only one of many uncertain parameters, econometric estimates may never be refined sufficiently to allow the ranking of policy options by a single criterion. Instead, more attention could be paid to the distributional effects and administrative costs that result from each reform. 
FIGURE I

WELFARE GAINS (W) FROM FOUR TAX REFORMS, AS

FUNCTIONS OF THE SAVING ELASTICITY $(\eta)$

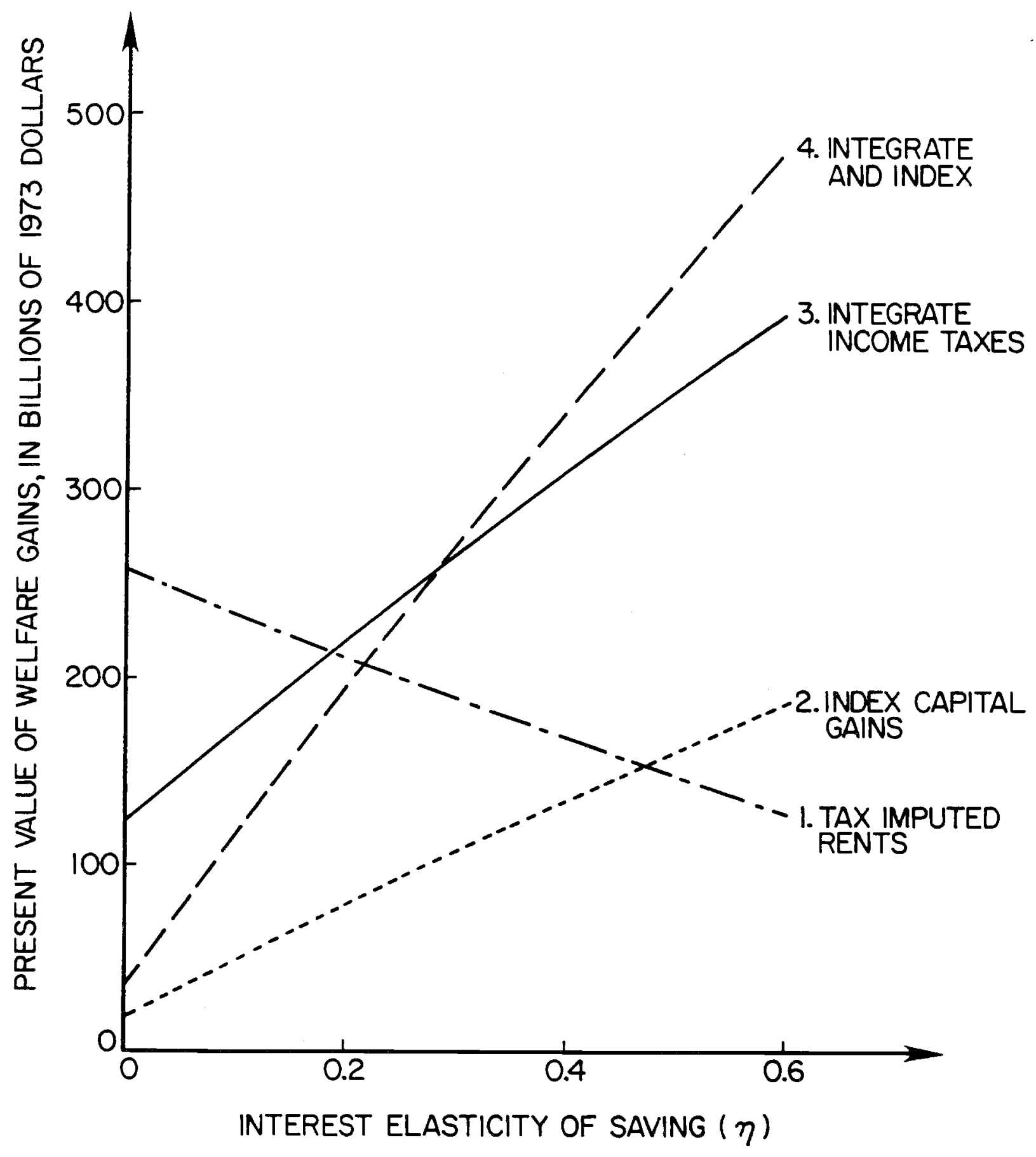




\section{Footnotes}

1. Lucas (1976) suggests a further problem. Values for $n$ are estimated from past data, and individual behavior may adjust in response to a policy change.

2. We provide only the briefest description of the general equilibrium model used in this paper, because more detail is readily available in Fullerton, King, Shoven, and Whalley (1981), and because great detail will soon become available in Ballard, Fullerton, Shoven and Whalley (1984).

3. Though the model provides some distributional results, consumer groups are differentiated by current income rather than by lifetime earnings. Because individuals move through several current income groups during their lifetimes, redistribution among such groups is a poor indicator of lifetime welfare. Finally, because capital is homogeneous and mobile in this model, no individuals suffer immediate capital gains or losses as the result of tax reform.

4. Welfare gains also depend upon the elasticity of labor supply with respect to the net wage, and on the elasticity of substitution between labor and capital in production. The uncompensated labor supply elasticity is set to 0.15 in this paper, while the substitution elasticities are chosen for each industry from estimates in the literature. 


\section{References}

Ballard, Charles L., Don Fullerton, John B. Shoven, and John Whalley (1984). Evaluation of United States Tax Policies with a Numerical General Equilibrium Mode1, Amsterdam: North-Holland Publishing Company, forthcoming.

Boskin, Michael J. (1978). "Taxation, Saving and the Rate of Interest," Journal of Political Economy, LXXXVI (Part 2, April), pp. S3-S27.

Denison, Edward F. (1958). "A Note on Private Saving," Review of Economics and Statistics, XL (August), Pp. 261-267.

Feldstein, Martin (1978). "The Welfare Cost of Capital Income Taxation," Journal of Political Economy, LXXXVI (Part 2, April), Pp. S29-S51.

Fullerton, Don, A.T. King, John B. Shoven, and John Whalley (1981). "Corporate Tax Integration in the United States: A General Equilibrium Approach," American Economic Review, LXXI-4 (September), pp . 677-691.

Harberger, Arnold C. (1962). "The Incidence of the Corporation Income Tax," Journal of Political Economy, LXX-3 (June), PP. 215-240.

Harberger, Arnold C. (1966). "Efficiency Effects of Taxes on Income from Capital," in Marion Krzyzaniak, ed., Effects of Corporation Income Tax, Detroit: Wayne State University Press.

Howrey, E. Philip and Saul H. Hymans (1978). "The Measurement and Determination of Loanable-Funds Saving," Brookings Papers on Economic Activity, Pp. 655-85.

Lucas, Robert E., Jr. (1976). "Econometric Policy Evaluation: A Critique," in K. Brunner and A. Meltzer, eds., The Phillips Curve and the Labor Market, Vo1. 1 of Carnegie-Rochester Conferences in Public Policy, a supplementary series to the Journal of Monetary Economics, Amsterdam: North-Holland Publications, pp. 19-46.

Starrett, David A. (1982). "Long Run Savings Elasticities in the Life Cycle Model," Factor Markets Workshop Research Paper No. 24, Stanford University.

Summers, Lawrence H. (1981). "Capital Taxation and Accumulation in a Life Cycle Growth Model," American Economic Review, LXXI-4 (September), pp. 533-544. 